\title{
Letters
}

Website: bmj.com

Email: letters@bmj.com

\section{Asymptomatic haematuria}

\section{All patients with haematuria should undergo cystoscopy}

EDITOR-Having just performed cystoscopy on a man of 36 who presented with bladder cancer five years ago, I am not reassured by Del Mar's so called evidence based survey of the likely diagnoses associated with occult haematuria. ${ }^{1}$

The quoted studies are likely to have missed cases of bladder cancer because not all patients underwent cystoscopy. Only 24 of 255 subjects in Ritchie et al's study underwent both upper tract imaging and cystoscopy. ${ }^{2}$ Among these, two cases of bladder cancer and one of bladder dysplasia (a premalignant condition) were found. The other 231 patients had not been adequately screened to exclude the presence of bladder cancer. There was no mention of long term follow up to confirm the absence of urological cancer in those who did not undergo initial cystoscopy. Similarly, not all of Hiatt and Ordonez's patients underwent a full urological evaluation, ${ }^{3}$ which prompts doubts about the accuracy of the performance statistics quoted in this paper.

Sultana et al performed cystoscopy and upper tract imaging in all patients referred

\section{Advice to authors \\ We prefer to receive all responses electronically, sent either directly to our website or to the editorial office as email or on a disk. Processing your letter will be delayed unless it arrives in an electronic form.}

We are now posting all direct submissions to our website within 24 hours of receipt and our intention is to post all other electronic submissions there as well. All responses will be eligible for publication in the paper journal.

Responses should be under 400 words and relate to articles published in the preceding month. They should include $\leqslant 5$ references, in the Vancouver style, including one to the BMJ article to which they relate. We welcome illustrations.

Please supply each author's current appointment and full address, and a phone or fax number or email address for the corresponding author. We ask authors to declare any competing interest. Please send a stamped addressed envelope if you would like to know whether your letter has been accepted or rejected.

Letters will be edited and may be shortened.

bmj.com

letters@bmj.com over one year with microscopic haematuria. In those aged over 50, five bladder cancers and one renal cancer were diagnosed in 126 patients. More recently Khadra et al performed full urological evaluation of 982 patients with occult haematuria. ${ }^{5}$ Altogether $5 \%$ had bladder cancer, $4 \%$ stone disease, and $0.3 \%$ renal cancer.

Current urological training emphasises the importance of obtaining a midstream specimen of urine, upper tract imaging, and particularly cystoscopy in all patients who have haematuria, whether microscopic or macroscopic and whether persistent or not Flexible cystoscopy can now be performed in minutes under local anaesthesia. I believe that there has to be a very good reason for not performing cystoscopy in patients with occult haematuria as this is likely to lead to missed diagnoses of bladder and renal cancer.

John Reynard consultant urologist

The Churchill Hospital, Oxford OX3 7LJ

jmruro@waitrose.com

\section{Del Mar C. Asymptomatic haematuria ... in the doctor BMJ 2000;320:165-6. (15 January.) \\ Ritchie CD, Bevan EA, Collier SJ. Importance of occul haematuria found at screening. BMJ 1986;292:681-3. \\ 3 Hiatt RA, Ordonez JD. Dipstick urinalysis screening, asymptomatic microhematuria, and subsequent urological cancers in a population-based sample. Cancer Epidemiol Biomarkers Prev 1994;3:439-43. \\ 4 Sultana SR, Goodman CM, Byrne DJ, Baxby K Microscopic haematuria: urological investigation using a Microscopic haematuria: urological inves \\ 5 Khadra MH, Pickard RS, Charlton M, Powell PH, Neal DE A prospective analysis of 1930 patients with hematuria to A prospective analysis of 1930 patients with hematuria to 524-7.}

\section{Scottish guidelines are different from} author's interpretation of best available evidence

EDITOR-Del Mar's paper on finding an evidence based approach for the investigation of asymptomatic haematuria when he was both investigator and subject was fascinating. I was surprised that he makes no mention of the use that guidelines could have been. No doctor can know the details of every condition or have the time to conduct a literature search for every situation that faces us. We are instead encouraged to use guidelines written by experts who have presumably taken the trouble to look at the evidence and recommend an approach based on this.

I was therefore surprised that the relevant Scottish guidelines recommend an approach diametrically opposite to the one that Del Mar found on the basis of the avail- able evidence. The guidelines of the Scottish Intercollegiate Guideline Network say that all people with asymptomatic haematuria require investigation including radiological imaging and cystourethroscopy. ${ }^{2}$ It is strange that one paper quoted by Del Mar as showing no need for investigation is interpreted in the Scottish guidelines as showing the value of investigation. ${ }^{3}$ It is worrying that the paper that Del Mar found most useful because it had a control group ${ }^{4}$ is not quoted by the Scottish guidelines.

In an interview in the $B M J$, Lord Naren Patel-the new chairman of Scotland's Clinical Standards Board-seemed proud of the guidelines of the Scottish Intercollegiate Guideline Network and would intend to use them as something against which a clinical service could be measured. ${ }^{5}$ It is worrying, particularly in the present medicolegal and political climate, that guidelines do not seem to based on the best evidence available.

James A D Finlayson general practitioner North Harris Medical Practice, West Tarbert, Isle of Harris, Western Isles HS3 3BG

1 Del Mar C. Asymptomatic haematuria ... in the doctor BMJ 2000;320:165-6. (15 January.)

2 Scottish Intercollegiate Guideline Network (SIGN). Irvestigation of asymptomatic microscopic haematuria in adults. Edinburgh: SIGN, 1997. (SIGN publication No 17.)

3 Ritchie CD, Bevan EA, Collier SJ. Importance of occult haematuria found at screening. $B M J$ 1986;292:681-3.

4 Hiatt RA, Ordonez JD. Dipstick urinalysis screening asymptomatic microhematuria, and subsequent urological cancers in a population-based sample. Cancer Epidemiol Biomarkers Prev 1994;3:439-43.

5 Christie B. Scotland's way to guarantee quality. BMJ 2000;320:78. (8 January.)

\section{Nephrological screening is important}

Editor-Del Mar's evidence based case report is unfortunate in reinforcing the all too common belief that haematuria is a surgical condition and that anything that is not cancerous is good. ${ }^{1}$

The author takes reassurance from two large studies suggesting that only a small proportion of patients presenting with microscopic haematuria will subsequently develop serious disease. ${ }^{2.3}$ Both studies, however, underestimate the importance of haematuria by not considering potential renal disease. In part, this is due to incomplete and short follow up, but urological bias is also a factor. Nephrological investigation of microscopic haematuria produces very different results. For example, Topham et al screened 165 patients with a mean age of 37.5 years and no adverse risk factors for renal disease and found important disease in 80; of these, 77 had abnormalities detected on renal biopsy, while only five had disease detected by uro- 
logical investigation (three had dual disease). ${ }^{4}$

What, then, is the renal perspective? Firstly, microscopic haematuria below the age of 45 is highly unlikely to represent urological disease. Indeed, the United Kingdom Renal Association recommends that all patients aged under 45 presenting with microscopic (or macroscopic) haematuria should in the first instance be referred for a nephrological, rather than a urological, opinion. ${ }^{5}$ Nephrological screening will rarely miss important surgical disease, and patients in whom clinical suspicion remains can always be selectively referred. Secondly, long term follow up is indicated for all patients with microscopic haematuria to identify those with low grade glomerular disease such as IgA nephropathy, where up to $40 \%$ will require dialysis 20 years after presentation. This is particularly important since effective treatment-aggressive antihypertensive control and reduction of proteinuria and (possibly) immunosuppression-exists in such conditions.

Lastly, Del Mar's acceptance of diagnostic uncertainty does not always match that of our patients. In experienced hands renal biopsy is extremely safe, with a high diagnostic yield. A recent audit in my practice showed that over three fifths of counselled patients presenting with microscopic haematuria elected to have biopsy despite knowing that it rarely alters immediate management. Their reasons included the desire for a definite tissue diagnosis, exclusion of other conditions, avoidance of repeated cycles of urological investigation, and the possible advantage of a diagnosis of a benign condition as regards insurance loading and having children.

Del Mar might wish to reconsider a nephrological cause for his haematuria, and patients should be offered an informed choice when considering the investigation of the symptom.

Peter A Andrews consultant nephrologist South West Thames Renal Unit, St Helier Hospital, Carshalton, Surrey SM5 1AA

pa.andrews@btinternet.com

1 Del Mar C. Asymptomatic haematuria ... in the doctor $B M J$ 2000;320:165-6. (15 January.)

2 Ritchie CD, Bevan EA, Collier SJ. Importance of occult haematuria found at screening. $B M J$ 1986;292:681-3.

3 Hiatt RA, Ordonez JD. Dipstick urinalysis screening asymptomatic microhematuria, and subsequent urological cancers in a population-based sample. Cancer Epidemiol Biomarkers Prev 1994;3:439-43.

4 Topham PS, Harper SJ, Furness PM, Harris KPG, Walls J, Feehally . Glomerular disease as a cause of isolated microscopic haematuria. O J Med 1994:87:329-35.

Scopic haematuria. QJ Med 1994;87:329-35.
5 Renal Association. Treatment of adult patients with renal fail-

ure. Recommended standards and audit measures. 2nd ed. Suffolk: Lavenham Press, 1997.

\section{Oxford Textbook of Medicine might have} helped author

EditoR-Del Mar found neither Harrison's Principles of Internal Medicine nor Bailey and Love's Short Practice of Surgery helpful in determining the chance of a man in his $40 \mathrm{~s}$ with persistent symptomless haematuria having a serious underlying disease. ${ }^{1} \mathrm{He}$ fared no better with the Cochrane Library, but two papers of 230 dredged from
Medline led him to pursue a policy of expectant observation, perhaps still with some misgivings.

Had he turned to the third edition of the Oxford Textbook of Medicine he would, we believe, have found the answer he sought more quickly. ${ }^{2}$ There he would have found that less than $2 \%$ of young people with haematuria without proteinuria have any significant disease (p 3145). He would also have found an algorithm showing different strategies of management and investigation depending on age over or under 45 (p 3147) and three references (p 3149) addressing the question he asks. ${ }^{3-5}$

We assume some error in the implication that 30 red cells per ml of urine constitutes haematuria, since such a figure is well within normal limits. Perhaps the figure was 30 cells per high power field or 30 cells per $\mu \mathrm{l}$, although that last figure is again not too remarkable.

In the Editor's choice for the issue containing Del Mar's article the editor refers to the (his italics) textbook Harrison's Principles of Internal Medicine. Might he now consider that there are British textbooks to rival Harrison's?

John G G Ledingham former professor of medicine, University of Oxford

22 Hids Copse Road, Cumnor Hill, Oxford OX2 9JJ

David A Warrell professor of tropical medicine and infectious diseases

Centre for Tropical Medicine, University of Oxford, John Radcliffe Hospital, Oxford OX3 9DU david.warrell@ndm.ox.ac.uk

David Weatherall regius professor of medicine, University of Oxford

Institute of Molecular Medicine, John Radcliffe Hospital

The authors are the editors of the Oxford Textbook of Medicine, 3rd edition.

1 Del Mar C. Asymptomatic haematuria ... in the doctor. BMJ 2000;320:165-6. (15 January.)

2 Weatherall DJ, Ledingham JGG, Warrell DA, eds. Oxfor textbook of medicine. 3rd ed. Oxford: Oxford University Press, 1996.

3 Britton JP, Dowell AC, Whelan PO. Dipstick haematuri and bladder cancer in men over 60: result of a community study. BMJ 1989;299:1010-2.

Froom P, Ribak J, Bombassat J. Significance of microhaematuria in young adults. BMJ 1984;288:20-1.

5 Kincaid-Smith P. Haematuria and exercise-related haematuria. $B M J$ 1982;285:1595-7.

\section{Some people just have asymptomatic} haematuria

EDITOR-I had a similar experience to Del Mar's, ${ }^{1}$ with haematuria, three years ago. I was an academic neonatologist in her $40 \mathrm{~s}$, interested in evidence based medicine. Using the keyword "EBM" I ran across Del Mar's article.

I found out that I had low grade persistent haematuria during compulsory medical examinations before starting work at new appointments. I was always told that I had a little blood in my urine, but in premenopausal women no one seems to take this seriously anyway. Then I had a bout of excruciating back pain with colic, which led to an investigation for renal stones in 1997. But no stones could be found, and my microscopic haematuria simply persisted after the attack. I then remembered that had had an investigation for loin pain and stones some 10 years before, with no stones found then either, while I was working as a resident in the United States.

Since I seemed to have symptoms every now and then, and my father had died of renal failure after glomerulonephritis, I went to a nephrologist with several questions: What is this? How are the attacks of colic related? What can I do to avoid these attacks (they're extremely uncomfortable and refractory to usual painkillers)? He examined my urine, confirmed microscopic haematuria, and came up with the diagnosis of loin pain/haematuria syndrome-an obviously descriptive diagnosis.

I then did my searches with the above keywords and came up with the finding of "thin basement syndrome"-a concept that makes a lot of sense to me. Some people (at the lower end of normal for thickness of the glomerular basement membranes?) just seem to allow erythrocytes through to their urine, and that seems to be a genetic trait. I offered these thoughts to an academic nephrologist, but he wasn't interested.

In the end I came to similar conclusions to Del Mar's:

- Some people (including academics) just have asymptomatic haematuria

- If it stays the same it's not much to worry about

- It's hard to stay away from investigations for renal calculi if you have back pain as well. I am grateful to Del Mar for his thorough confirmation of the first point.

Juliane Hentschel neonatologist

Women's Hospital, Inselspital, University of Berne, Ch-3012 Berne, Switzerland

juliane.hentschel@insel.ch

\section{Del Mar C. Asymptomatic haematuria .... in the doctor.} BMJ 2000;320:165-6. (15 January.)

\section{Author's reply}

EDITOR-The piece of evidence that was so compelling for me was the fact that having microscopic haematuria was no more predictive of unpleasant urological diagnoses than not having it. ${ }^{1}$ It suggests that the presence of invisible blood in the urine means I am not more likely to have urological cancer. Of course I am still at risk from this (as we all are), but no more than if I had normal urine.

"I am very sorry, but the test of your urine showed no microscopic blood; you have a small chance of having urological cancer, and we will need to start investigations. Some of these are expensive and somewhat unpleasant." Surely no one would advocate this?

Neither am I inclined to submit myself for a renal biopsy. Andrews offers too little evidence in support of renal biopsy. My blood pressure is fine, and I have no proteinuria. Should either change I will act straight away. I would have to be convinced that I would benefit from immunosuppressive treatment at this early stage even if I had IgA nephropathy. The only alteration to my doing nothing is a slightly increased monitoring of my blood pressure and occa- 
sional testing of my urine for the development of increasing blood content or of proteinuria. The motto should be "don't do a test unless you will act on the result."

The Oxford Textbook of Medicine is very good. But it does not refer to this compelling evidence either. In fact, the algorithm to which its editors direct attention suggests further investigation (imaging and long term follow up for the under 50 s and, in addition, "look for carcinoma" in those aged 50 and over, which presumably means carry out cystoscopy). This is similar advice to that in competing texts. (Ledingham et al are correct in pointing out my error: the urine microscopy test showed 30 red cells per $\mu \mathrm{l}$, not per $\mathrm{ml}$ as given in the article.)

Textbooks, like guidelines, may hide much of the process of making guidelines. This may be one reason why they are poorly implemented. ${ }^{2}$ It is as important to know the why of the guidelines as the what. Sometimes it is better to make the decision based directly on the information found. I choose to do nothing with this information. Others will choose differently. To allow patients and their doctors to make informed decisions together they must have the best information about the alternatives available and accessible to them, not merely cookbook recipes to be followed.

Chris Del Mar professor of general practice University of Queensland, Queensland 4077,

Australia

c.delmar@mailbox.uq.edu.au

1 Hiatt RA, Ordonez JD. Dipstick urinalysis screening, asymptomatic microhematuria, and subsequent urological cancers in a population-based sample. Cancer Epidemio Biomarkers Prev 1994;3:439-43.

2 Cabana MD, Rand CS, Powe NR, Wu AW, Wilson MH Abboud PA, et al. Why don't physicians follow clinical practice guidelines: a framework for improvement. JAMA $1999 ; 282: 1458-65$

\section{Long term benefits need to be taken into account when evaluating family support projects}

EDITOR-Many voluntary sector initiatives offer community support, but we are aware that not all those who need help are ready to receive it. The Amalthea Project, discussed by Grant et al, was developed to bridge this gap by facilitating access to the voluntary sector from primary care. ${ }^{1}$ Grant et al's evaluation of this project makes a real contribution, measuring both the benefit to patients with psychosocial problems and the costs of such projects.

Grant et al confirmed that using referrals facilitators results in both clinical and social improvements for patients, but they concluded that it costs more than the usual care offered by general practitioners. The experiences of the Hackney WellFamily Service, a family support project we developed jointly with the Family Welfare Association, suggest that this is shortsighted. It fails to take into account the long term benefits to the community and the consequent reduction in the burden on all support services if the cycle of deprivation can be broken.

The WellFamily Service also offers referral facilitation but combines this with practical and emotional support to help families build their own resources and find ways around their problems. This approach has been well received by people of different ages and ethnic groups, and it has reached families who might otherwise have been excluded by poverty, limited education, or lack of confidence.

In an 18 month evaluation, 113 patients or families used the service and 20 participated in semistructured interviews. ${ }^{2}$ Several themes emerged. We found that focusing on the whole family provided an opportunity to support those who were hard to reach, such as the mother of a delinquent teenager, and that providing non-statutory help may overcome a client's resistance to authority and give those deemed to be "at risk" a sympathetic hearing in an accessible environment.

Another advantage of a practice based service is the change that it facilitates within primary care; in our case, this has contributed to the development of a more family centred approach throughout the primary care team. Our approach emphasises wellness and the normalisation of help seeking, concepts that also underpin the work of health visitors. Because of these similarities we have also explored working with health visitors to expand the service, an approach which draws on a government white paper. ${ }^{3}$ Grant et al have shown that such a service incurs costs that are not recouped by primary care, but if services like the Amalthea Project, or like ours, are to be made more widely available, we need mechanisms that allow us to share the costs between the social and healthcare budgets.

Clare Goodhart general practitioner principal Statham Grove Surgery, London N16 9DP

Jonathan Graffy senior lecturer

Department of General Practice and Primary Care, Queen Mary and Westfield College, London E1 4NS j.graffy@qmw.ac.uk

1 Grant C, Goodenough T, Harvey I, Hine C. A randomised controlled trial and economic analysis of a referrals facilcor 2000;320:419-23. (12 February.)

2 Goodhart C, Layzell S, Cook A, Graffy J. Family support in general practice. JR Soc Med 1999;92:525-8.

3 Home Office. Supporting families: a consultation document. www.homeoffice.gov.uk/vcu/suppfam.htm (accessed June)

\section{Organ transplantation and discrimination}

Treatment should be available to everyone

EDITOR-In examining the selection process for organ transplantation, Masterston is correct in stating that doctors share the public's prejudice against people with mental illness. ${ }^{1}$ In a survey of American transplant centres, active schizophrenia was an "absolute contraindication" to transplantation in $92 \%$ of cardiac units, $67 \%$ of liver units, and $73 \%$ of renal units. ${ }^{2}$ Controlled schizophre- nia was relatively contraindicated in $51 \%$, $65 \%$, and $62 \%$ respectively. During the first 11 years of a heart transplantation programme in Montreal, 226 transplants were completed and 28 people were denied the procedure on the basis of a psychiatric diagnosis." Seven of these 28 people had continuing alcohol or drug misuse, six had non-compliance with treatment, and two each had multiple suicide attempts, borderline personality, "unrealistic expectations," or mental retardation. Interestingly, when the American Psychiatric Association issued a statement on discrimination against its patients, it focused on employment, ignoring discrimination in the health service. ${ }^{4}$ Orentlicher had previously pointed out that denial of transplantation on the basis of schizophrenia or non-compliance violated the Americans with Disabilities Act.

Masterston also comments on the increased mortality (all causes) in people with all mental disorders ${ }^{1}$ but fails to challenge the medical profession about the contribution doctors make to these deaths in using assumptions and value judgments to deny access to treatments such as transplantation. If an investigation or treatment is medically justified then it should be available to everyone, regardless of any psychiatric label.

Peter Byrne consultant psychiatrist Community Mental Health Team, Folkestone CT19 5HN

byrnepr@nascr.net

1 Masterston G. Psychosocial factors in selection for liver transplantation. $B M J$ 2000;320:263-4. (29 January.)

2 Levenson JL, Oldbrisch ME. Psychosocial evaluation of organ Phip

Phipps L. Psychiatric evaluation and outcomes in candidates for heart transplantation. Clin Invest Med

4 American Psychiatric Association. Position statement on discrimination against persons with previous psychiatric treatment. Am J Psychiatry 1997;154:7.

5 Orentlicher D. Psychosocial assessment of organ transplant candidates and the Americans with Disabilities Act Gen Hosp Psychiatry 1996;18(suppl 6):5-12

\section{Patients with hepatitis B should not be} given low priority

EDITOR-The editorial by Masterton on psychosocial selection of patients for liver transplantation was timely and informative. Liver transplantation depends on public support for continued organ donation and state support in running a transplantation programme. It is vital that debate takes place concerning patient selection.

It is right that in assessing a patient's suitability for a transplant clinicians emphasise the prognosis after transplantation. We are therefore concerned that Masterton said that patients with chronic hepatitis B virus infection have a poor outcome following transplantation and should therefore, by implication, be given low priority for transplantation. In the past, recurrence of hepatitis B virus infection has been problematic after liver transplantation and has been associated with fibrosing cholestatic hepatitis, accelerated cirrhosis, and a three year survival of only $44 \%$ in those patients with reinfection of the graft. ${ }^{2}$ However, the introduction of hepatitis B immunoglobu- 
lin, ${ }^{3}$ and then of lamivudine prophylaxis, ${ }^{4}$ has been shown to reduce considerably the replication of the hepatitis B virus after transplantation, and the rate of graft loss related to the hepatitis $B$ virus.

Lamivudine treatment, either alone or in combination with hepatitis B immunoglobulin, has been shown to be associated with $>97 \%$ patient survival after a median follow up of more than two years. ${ }^{5}$ Longer term follow up will confirm whether these considerably improved responses are maintained. The development of variants of the hepatitis B virus that are resistant to lamivudine presents a challenge, which it is hoped may be minimised with the development of other combinations of antiviral agents.

Nevertheless, the introduction of new treatments over the past five years has led to a greater improvement in medium term survival of patients given a transplant because of hepatitis B than in patients with any other single indication. Therefore, we do not believe that patients who need liver transplantation and whose liver disease is caused by hepatitis B virus infection should be given low priority.

George Webster clinical research fellow gwebster@rfc.ucl.ac.uk

Eleanor Barnes clinical research fellow Andrew Burroughs consultant physician and hepatologist

Geoffrey Dusheiko professor of medicine Centre for Hepatology, Royal Free and University College Medical School, Royal Free Campus, London NW3 2PF

1 Masterton G. Psychosocial factors in selection for liver transplantation. BMJ 2000;320:263-4. (29 January.)

2 Samuel D, Muller R, Alexander G, Fassati L, Ducot B, Benhamou JP, et al. Liver transplantation in European patient with the hepatitis B surface antigen. $N$ Engl J Med 1993;329:1842-7.

3 McGory RW, Ishitani MB, Oliveira WM, Stevenson WC, McCullough CS, Dickson RC, et al. Improved outcome of orthotopic liver transplantation for chronic hepatitis B cirrhosis with agoressive passive immunization. Transplantation 1996;61:1358-6

4 Grellier L, Mutimer D, Ahmed M, Brown D, Burroughs AK, Rolles K, et al. Lamivudine prophylaxis against reinfection in liver transplantation for hepatitis $\mathrm{B}$ cirrhosis reinfection in liver transpl

5 Nery JR, Weppler D, Rodriguez M, Ruiz P, Schiff ER, Tzakis AG. Efficacy of lamivudine in controlling hepatitis B virus AG. Efficacy of lamivudine in controlling hepatitis B virus
recurrence after liver transplantation. Transplantation 1998;65:1615-21.

\section{Midline episiotomy and anal incontinence}

\section{Training is needed in the recognition and} repair of perineal trauma

EDITOR-The finding by Signorello et al that midline episiotomy may impair anal continence is valuable and highlights the effect of perineal trauma on the anal continence mechanism. ${ }^{1}$ The authors acknowledge the limitations of the study, which was retrospective, non-randomised, and may have included misclassifications of perineal trauma.

We investigated 161 nulliparous women in the third trimester and 12 weeks post partum. A symptom questionnaire and anorectal investigations were performed at both visits and anal endosonography was performed post partum.
Women with an intact perineum had a mean squeeze pressure of $105.8 \pm 26.4$ $\mathrm{mmHg}$, those who sustained second and third degree perineal tears had a mean squeeze pressure of $92.3 \pm 30.3 \mathrm{mmHg}$ $(\mathrm{P}=0.022)$, and those who had mediolateral episiotomies had a mean squeeze pressure of 92.2 $\pm 29.7 \mathrm{mmHg}(\mathrm{P}=0.032)$.

Sphincter trauma was associated with perineal trauma at delivery: of 59 women with second or third degree tears, $41(69 \%)$ had sphincter trauma versus 39 out of 97 women $(40 \%)$ with an intact perineum $(\mathrm{P}=0.001)$. Sphincter trauma was also significantly more common in women who underwent vaginal delivery: 58 out of 130 $(45 \%)$ women had sphincter defects in the vaginal delivery group versus 1 out of 26 women $(4 \%)$ women who underwent a caesarean section $(\mathrm{P}=0.0005)$. However, the difference between our study and that of Signorello et al is that the patients in our study had a mediolateral and not a midline episiotomy, and it is well known that midline episiotomy is associated with a higher risk of extension to the anal sphincter.

Our study has confirmed previous reports that show that the incidence of sphincter damage increases considerably when an episiotomy occurs together with a perineal tear. ${ }^{3}$ The association of any perineal trauma, either an episiotomy or a spontaneous tear, with sphincter defects has important implications for obstetric practice as sphincter trauma has been linked directly to the development of anal incontinence. ${ }^{4}$ Methods to minimise perineal trauma such as the use of the ventouse rather than the forceps and the correct management of the active second stage once the head is crowning should be encouraged.

Recognition of perineal trauma is known to be poor and this may lead to inadequate repair and predispose to the development of incontinence. ${ }^{5}$ Doctors and midwives both need improved and focused training in the recognition and repair of sphincter trauma.

Charlotte Chaliha specialist registrar

Department of Obstetrics and Gynaecology,

Kingston Hospital, Kingston upon Thames, Surrey KT2 7QB

Abdul H Sultan consultant obstetrician and gynaecologist

Department of Obstetrics and Gynaecology, Mayday University Hospital, Croydon, Surre CR7 7YE

I Signorello LB, Harlow BL, Chekos AK, Repke JT. Midline episiotomy and anal incontinence: retrospective cohort episiotomy and anal incontinence: re
study. BMJ 2000;320:86-90. (8 January.)

2 Chaliha C, Kalia V, Sultan AH, Monga AK, Stanton SL. Chaliha C, Kalia V, Sultan AH, Monga AK, Stanton SL. Anal function: effect of

Urodyn 2000;17:417-8.
3 Frudinger A, Bartram CI, Spencer JAD, Kamm MA. 3 Frudinger A, Bartram CI, Spencer JAD, Kamm MA. Perineal examination as a predictor of underlying external
anal sphincter damage. $\mathrm{Br} J$ Obstet Gynaecol anal sphincter damage. $\mathrm{Br} \quad J$ Obstet Gynaecol
1997;104:1009-13.

4 Sultan AH, Kamm MA, Hudson CN, Thomas JM, Bartram CI. Anal sphincter disruption during vaginal delivery. $N$ Engl J Med 1993;329:1905-11

5 Sultan AH, Hudson CN. Are junior doctors and midwives adequately trained to repair the perineum? J Obstet Gynaecol 1995; 15:19-23.

\section{A prospective study is needed}

EDITOR-I cannot understand why Signorello et al's study, which reached its end point after six months, was not set up prospectively. ${ }^{1}$ Although the answers given by the study seem to be valid, the results would have been less liable to recall biases if data had been gathered using study specific clinical research forms during delivery and if questionnaires on signs and symptoms had been provided at three and six months post partum. The responses might have been higher in number, more accurate, and returned sooner, so that even the study probably would not have lasted as long.

Kees Boer academic specialist

Academic Medical Centre, Department of Obstetrics and Gynaecology, University of Amsterdam, 1100 DE Amsterdam, Netherlands k.boer@amc.uva.n

1 Signorello LB, Harlow BL, Chekos AK, Repke JT. Midline episiotomy and anal incontinence: retrospective cohor study. BMJ 2000;320:86-90. (8 January.)

\section{Results should be interpreted with caution in British context}

EDITOR-Signorello et al raise important questions about the use of episiotomies and the detrimental effect on anal continence. ${ }^{1}$ Unfortunately, their study may not be relevant to practice in Europe. Women in their study all had a midline episiotomy, which is the preferred procedure in the United States.

In a midline episiotomy a vertical incision is made in the direction of the anal sphincter. Third and fourth degree tears have been reported to occur in more than $20 \%$ of women having midline episiotomies. ${ }^{23}$ In the United Kingdom and most of Europe a mediolateral episiotomy is preferred, which has a much lower risk of damaging the anal sphincter. ${ }^{2}$ The incision is directed towards the ipsilateral ischial tuberosity, away from the anal sphincter. This could reduce rather than increase the risk of anal incontinence. ${ }^{4}$

In addition, several methodological issues are worth consideration. A greater proportion of questionnaires were completed in the episiotomy group than in the group with intact perineum (14\% more; $95 \%$ confidence interval $(6 \%$ to $21 \%))$ and $11 \%$ more $(3 \%$ to $18 \%)$ were completed in the group with tear than in the group with intact perineum. This could represent an important source of bias and in a worst case scenario could have a large effect on the results.

Secondly, the design of the study was to send a questionnaire at six months post partum requesting recall of symptoms at three months. It is certainly possible that recall could relate to symptoms experienced nearer to the delivery, which may account for the difference in results between the two time periods. It would seem more logical to send questionnaires at three months and follow up forms at six months.

Thirdly, the authors report that the risk of faecal incontinence at six months is tripled and that the risk of flatus incontinence at three months is doubled, with confidence intervals that include the null value. The results are consistent with no effect and to report them in this way is misleading. 
In conclusion, the findings of this study, while interesting, ought to be interpreted with caution in the British context.

M S Mills consultant obstetrician and gynaecologist Deirdre J Murphy lecturer in clinical obstetrics

Division of Obstetrics and Gynaecology, St

Michael's Hospital, Bristol BS2 8EG

D.J.Murphy@bristol.ac.uk

1 Signorello LB, Harlow BL, Chekos AK, Repke JT. Midline episiotomy and anal incontinence: retrospective cohor episiotomy and anal incontinence: re

2 Coats PM, Chan KK, Wilkins M, Beard RJ. A comparison

between midline and mediolateral episiotomies. Br J Obstet between midline and mediol
Gynaecol 1980:87:408-12.

3 Bynaecol 1980;87:408-12. episiotomy and delivery position with deep perineal aceration during spontaneous delivery in nulliparous women. Am J Obstet Gynecol 1989;160:294-7.

4 Poen AC, Felt-Bersma RJ, Dekker GA, Deville W, Cuesta MA, Meuwissen SG. Third degree obstetric perineal tears risk factors and the preventive role of mediolateral episiotomy. Br J Obstet Gynaecol 1997;104:563-6.

\section{Is episiotomy ethically acceptable?}

EDITOR-The guiding tenet of the physician is "primum non nocere"-firstly do no harm. It seems inconceivable that an operation that inflicts severe harm on women would continue to be practised wholesale, despite medical evidence of its potentially detrimental effects. Yet episiotomy is one such operation.

The recent study by Signorello and colleagues shows a considerable increase in faecal and flatus incontinence in women who have had an episiotomy. ${ }^{1}$ These findings reinforce the overwhelming body of evidence which continues to show that episiotomy is associated with severe maternal morbidity and is rarely of any benefit. The need for immediate delivery in the face of acute fetal distress is one of the few remaining indications for episiotomy. The concept that episiotomy prevents third and fourth degree tears of the perineum or protects the pelvic floor has been repeatedly disproved. $^{2}$ Faecal and flatus incontinence, third and fourth degree perineal lacerations, a fear of future childbirth, severe dyspareunia, and blood loss which exceeds that at caesarean section $^{3}$ are major complications associated with this unfortunately too often performed procedure.

Episiotomy seems to be totally contrary to the physician's principle of beneficence and non-maleficence. We can therefore ask whether indiscriminate performance of episiotomy is ethically acceptable or medically justifiable. Given the risks associated with the procedure, episiotomy should be considered to be a major operation, and practitioners considering performing one should carefully weigh the risks associated with the procedure against any perceived benefits. The day will come in the near future when practitioners will have to defend the complications incurred as a result of episiotomy. As medical knowledge advances, it is conceivable that episiotomy may one day join such extinct operations as blood letting, high forceps delivery, and symphysiotomy, which are now considered crude and barbaric but were once widely practised, as shown in the books of medical antiquity. As a recent reviewer aptly put it," "episiotomy has 'been weighed in the scales and been found wanting." "
K Olayinka Oyelese resident YinkaMD@aol.com

Amy Porter chief resident

Clifford Wai chief resident

Department of Obstetrics and Gynecology,

Georgetown University Medical Center,

Washington, DC 20007, USA

1 Signorello LB, Harlow BL, Chekos AK, Repke JT. Midline episiotomy and anal incontinence: retrospective cohort study. BMJ 2000;320:86-90. (8 January.)

2 Woolley RJ. Benefits and risks of episiotomy: a review of the English-language literature since 1980. Obstet Gyneco Surv 1995;50:806-20.

3 Sarfati R, Marechaud M, Magnin G. Comparison of blood loss during cesarean section and during vaginal deliver with episiotomy. J Gynecol Obstet Biol Reprod 1999;28:48-54.

\section{Diagnosing and treating depression}

\section{Treatment is often challenging}

EDITOR-On reading Kendrick's article, ${ }^{1}$ I was reminded of the notion that individuals seek out a field of medicine that suits the workings of their brain and personality. Surgeons tend to be results oriented, enjoy solving concrete problems with concrete answers, and need closure (no pun intended). Internists have a high tolerance for "not knowing," living with uncertainty, and allowing problems to stay open, dynamic, a work in progress. Chronic disease is recognised as the human condition. Family practitioners are willing to tackle any problem to the best of their ability, and they can live with the idea that they need to learn more and more to improve their skills. They tend to find the time to upgrade their knowledge in seminars, journals, and other forms of courses. They are typically not deeply versed in any particular field, psychiatry included.

Depression is a complex illness. Without the sense of "psychological mindedness" that often directs a person into the mental health fields, it is difficult to grasp the ful picture of the syndrome of depression. Treatment is often challenging and not as simple as might be implied by the few hours of instruction delivered to the willing participants in the trial.

The choice of standard antidepressant in the trial is certainly open to some criticism: tricyclics have retreated to an occasional choice in the new world of psychopharmacological agents. We now expect full remission of the syndrome of depression and should seldom settle for less. Psychotherapy as an additional treatment modality has been shown to be a useful too in the treatment plan and should not be overlooked or relegated to the history books.

Unfortunately, the proper treatment requires considerable training and experience and a great deal of time-commodities in short supply in the world of the primary care physician. Lest I seem negative and overly critical, I believe that primary care physicians can have a more effective role in the treatment of depression, but I do not think that the training approach meets the requirements for developing that role effectively.

Ward Tolbert Smith medical director Pacific North West Clinical Research Center, Summit Research Network, 1849 NW Kearney Street, Portland, OR 97232, USA wsmit95963@aol.com

1 Kendrick T. Why can't GPs follow guidelines on depression? BMJ 2000;320:200-1. (22 January.)

\section{Educating family physicians to recognise depression}

EDITOR-We read Kendrick's editorial with interest, ${ }^{1}$ as we recently conducted and reported a randomised trial of an educational strategy to improve family physicians' detection and management of depression. ${ }^{2}$ Using patients' clinical state as a measure of outcome, we found at six months a modest but beneficial effect of the educational strategy on patients with depression. Furthermore, after 18 months, the depression rating scores of patients from the control group deteriorated slightly, whereas those of patients from the intervention group remained stable. ${ }^{3}$ Doctors who received the intervention had a higher rate of diagnosing depression and a higher rate of referral to psychiatrists and other health professionals than did family doctors who were in the control group. A higher proportion of patients whose doctors had received the intervention remained on their antidepressant drugs for the duration of the study.

Although we agree with Kendrick that the spectrum and course of depression in primary care is different from the "major depressive disorder" that is targeted by the clinical practice guidelines, we are more optimistic than he, as our trial seemed to have a better outcome than many of the trials he described. Perhaps the prescribing pattern of family doctors is different in Canada; we found that 133 of 147 patients who were diagnosed as suffering from depression were treated with antidepressant medication and that $120 \quad(90 \%)$ took selective serotonin reuptake inhibitors. We think that educational sessions for small groups of family doctors and close liaison with psychiatric colleagues can greatly improve the recognition of depression and the care of people with depression.

Graham Worrall associate professor of family medicin Centre for Rural Health Studies, Whitbourne, Nfld A0B 3K0, Canada

gworrall@morgan.ucs.mun.ca

John Angel clinical associate professor of psychiatry Department of Psychiatry, Memorial University of Newfoundland, Health Sciences Centre, St John's, Nfld A1B 3V6, Canada

1 Kendrick T. Why can't GPs follow guidelines on depression? BMJ 2000;320:200-1. (22 January.)

2 Worrall G, Angel J, Chaulk P, Clarke C, Robbins M. Effectiveness of an educational strategy to improve family physicians' detection and management of depresssion: a randomized controlled trial. Can Med Assoc J 1999;161: $37-40$.

3 Worrall G, Elgar F, Robbins M. Improving management of depression [letter]. Can Med Assoc J 2000;162:316. 


\section{Can primary care improve care for depressed patients?}

EDITOR-Kendrick questions the evidence base for guidelines on depression because Thomson and colleagues found that educational interventions did not improve outcomes in depression. ${ }^{12}$ However, Wells et al found that quality improvement programmes in a managed care setting in the United States can improve the care of patients with depression. ${ }^{3}$ Perhaps it is how we try to change practice that is at issue here and not the dynamic evidence base of guidelines. Primary care practitioners need to know whether there is anything they can do now to help depressed patients.

Kendrick noted that "most patients do not continue treatment for the recommended duration and that this may explain the consistent finding that recognition of depression and drug treatment in primary care is not associated with a better outcome." This implies that if compliance with treatment could be improved then outcomes would improve. We believe that a more systematic multidisciplinary model can achieve this.

In our typical urban practice a nurse runs a clinic for patients with depression. The clinic addresses the needs of patients and their families from a holistic framework and coordinates appropriate referrals to other agencies, including counselling. ${ }^{4}$ The nurse monitors progress and encourages compliance with medication and other treatment. As a result compliance is enhanced and considerable improvements in mood have been shown.

In complex organisations dealing with complex problems, educational interventions on their own are often insufficient to change behaviour. ${ }^{5}$ Although the evidence base needs constant improvement, primary care can get on with introducing systematic organisational changes to support patients' compliance with treatment.

\section{Michael McCullagh GP principal \\ Sally Gardner practice nurse \\ Orchard Medical Practice, Ipswich IP4 2PU \\ mmccullagh@msn.com}

1 Kendrick T. Why can't GPs follow guidelines on depression? BMJ 2000;320:200-1. (22 January.)

2 Thompson C, Kinmonth AL, Stevens L, Peveler RC, Stevens A, Ostler KJ, et al. Effects of a clinical-practice guideline and practice-based education on detection and outcome of depression in primary care: Hampshire outcome of depression in primary care: Hampshire
depression project randomised controlled trial. Lancet depression project randomised controlled trial. Lance 2000;355:185-91

3 Meredith L, Unützer J, Miranda J, Carney MF, Rubenstein LV. Impact of disseminating quality improvement programs for depression in managed primary care. JAMA 2000;283:212-20.

4 McCullagh MG, Gardner S. Practice nurses and treatmen of depression. Br J Gen Pract 1998;48:1091-2.

5 Allery LA, Owen PA, Robling MR. Why general practitioners and consultants change their clinical practice: a critical incident study. BMJ 1997;314:870.

\section{A holistic approach is recommended}

EDITOR-Kendrick raises several issues that we wish to challenge. ${ }^{1}$ General practice is a specialty of uncertainty and a decision to ascribe "caseness" may be difficult in many patients who visit the surgery. In psychiatry, where continuum models abound for psychosis, affective symptoms, and other behaviour, caseness may also be viewed in varying shades of grey. However, valid and reliable classification systems, such as the ICD-10 (international classification of diseases, 10th revision) and the Diagnostic and Statistical Manual of Mental Disorders, fourth edition, help in this respect. Strict criteria emphasising severity, duration of symptoms, and impact on life all help to define what is illness and what is not.

However, evidence shows that even patients with dysthymia can benefit from using antidepressants. ${ }^{2}$ A doctor's willing ness to treat can be rewarded with a considerable overall improvement in symptoms, although this may occur in stages. Classifications such as endogenous versus nonendogenous depression are less in vogue; they are less valid and do not predict response to treatment with antidepressants.

A reluctance to initiate treatment in the face of adverse social factors is a troublesome misconception. We should all try to take a holistic view of our patients. The Royal College of General Practitioners emphasises a biopsychosocial model for the formulation of patients' problems. To conceptualise a person's symptoms as being a result of their social difficulties is also reductionist. This is incongruent in a profession traditionally criticised for adopting an isolated biological viewpoint.

Certainly, unresolved social problems can be a perpetuating factor in depression. But for aetiology to prejudice access to treatment is surely wrong. Some patients may start to solve problems more effectively when their depressive symptoms are lessened and they can begin to see ways out of their social quagmire.

We wonder whether the Hampshire study $^{3}$ is not so much an issue of guideline failure as another demonstration of systematic avolition and disillusion with depression management. If we can make our depressed patients even partially better with drug treatment, we should strive to do so with energy and optimism.

S Llewellyn-Jones senior house officer in psychiatry library@cefn-coed-lib.demon.co.uk

P Donnelly consultant in community psychiatry Cefn Coed Hospital, Swansea SA2 0GH

\section{Kendrick T. Why can't GPs follow guidelines on depression? BMJ 2000;320:200-1. (22 January.) \\ 2 Hellerstein DJ, Yanowitch P, Rosenthal J, Wallner Samsta L, Maurer M, Kasch K, et al. A randomised double-blind study of fluoxetine versus placebo in the treatment of dys- thymia. Am J Psychiatry 1993;150:1169-75. \\ 3 Thompson C, Kinmonth AL, Stevens L, Peveler RC, Stevens A, Osterler KJ, et al. Effects of a clinical-practic guideline and practice-based education on detection an outcome of depression in primary care: Hampshire depression project randomised controlled trial. Lancet 2000;355:185-91.}

\section{Learning to look at the illness from both} sides

EdITOR-Having taken antidepressants for most of the past eight years, I feel qualified to respond to Kendrick's article. ${ }^{1}$

Firstly, depression is not always easy to diagnose, even if major (my main symptom was depersonalisation), and the correct diagnosis may take some time.
Secondly, amitriptyline is foul. It tastes awful, makes you sleepy, and gives you a tendency to pass out at therapeutic doses.

Thirdly, cognitive behavioural therapy helps up to a point, but the times when you really need to use it (because you're falling down a black hole) are the times you can't use it, because you are incapable of meaningful logical thought.

And finally, there is the issue of compliance. Every time you take an antidepressant, it is a reminder that you are "weird," that your thought patterns are abnormal, and that to function normally you depend on medication. Because you are desperate to seize on any hope that you have returned to "normal" is it any surprise that medication is stopped sooner than recommended?

Helen Johnson senior house officer in accident and emergency

Lamlash Medical Centre, Lamlash, Isle of Arran KA27 8NS

Helen.M.Johnson@tesco.net

1 Kendrick T. Why can't GPs follow guidelines on depression? BMJ 2000;320:200-1. (22 January.)

\section{Author's reply}

EdITOR-Tolbert Smith has a point about the difficulty of changing behaviour through relatively brief education, but our current education system cannot deliver much more than this. The Hampshire depression project used an inpractice programme conforming to good educational principles, which was well received by practitioners who were self selected for their interest in depression. ${ }^{1}$ Its conclusions that improvements in recognition and treatment of depression in primary care are unlikely to be achieved through education alone deserve to be taken seriously.

The Canadian trial reported by Worrall and Angel was not directly comparable as the intervention was a combination of education and increased access to a psychiatrist, so the modest benefits found may have resulted from the extra input from the specialist. They reported no notable difference between the intervention and control groups in the proportion of patients who completed six months of antidepressant treatment. Also there was no attempt to measure changes in doctors' sensitivity by comparing their assessment with that of a screening tool, so they could not assess whether there were improvements in doctors' rates of detection of depression-although the doctors in the intervention group reported more cases to the project team, perhaps they may have had more incentive to do so than the doctors in the control group.

I agree with McCullagh and Gardner that there are effective interventions to improve compliance with treatment and outcome for those patients who truly need drugs. ${ }^{3}$ I am interested to hear about their practice clinic and have also suggested recently that practices might set up nurse led clinics to improve management of depression. ${ }^{4}$

Llewellyn-Jones and Donnelly are right that we should not discount the possibility of 
treating people with drugs in the face of unresolved social problems, and I did not wish to seem nihilistic, but Johnson reminds us that we need to listen to our patients, who are telling us something about the acceptability of treatment. We must be reasonably sure that we are doing good before we press treatment. Given the high prevalence of depressive symptoms among our patients and the high rate of resolution without specific treatment, the most important question is, who is likely to benefit from treatment? We have almost no primary care research on the effectiveness of antidepressant drugs for different levels of severity of depression and in the presence or absence of continuing social difficulties.

Patients in secondary care are as a group more severely depressed, are therefore perhaps more likely to accept drug treatment, and are more likely to need drugs to get better regardless of any changes in their social circumstances. The prevalence of major depression is proportionately much lower in primary care than in secondary care, which means that the positive predictive value (in terms of predicting the need for drug treatment) of meeting the symptom count will also be lower ${ }^{5}$-there will be more false positives in a population that hasn't already been selected for severity of depression by the referral process, and more patients with milder depression who would have less to gain from taking antidepressants and might be more responsive to psychosocial interventions.

The idea that guidelines for assessment and drug treatment developed in secondary care can simply be applied directly to primary care populations is therefore clearly questionable. I remain unsurprised that guideline based education does not lead to improvements in case detection and outcome when the guidelines do not adequately tell us whom to treat.

Tony Kendrick professor of primary medical care University of Southampton Aldermorr Health Centre, Southampton SO16 5ST

ark1@soton.ac.uk

1 Thompson C, Kinmonth AL, Stevens L, Peveler RC, Stevens A, Ostler KJ, et al. Effects of a clinical-practice guideline and practice-based education on detection and outcome of deppractice-based education on detection and outcome of depression in primary care: the Hampshire depression project randomised controlled trial. Lancet 2000;355:185-9

2 Worrall G, Angel J, Chaulk P, Clarke C, Robbins M. Effectiveness of an educational strategy to improve family physicians' detection and management of depression: a randomized controlled trial. Can Med Assoc J 1999;161:37-40.

3 Peveler R, George C, Kinmonth A-L, Campbell M, Thompson C. Effect of antidepressant drug counselling and information leaflets on adherence to drug treatment in primary care: randomised controlled trial. $B M J$ 1999;319:612-5

4 Kendrick T Depression management clinics in general practice? Some aspects lend themselves to the mini-clinic approach. BMJ 2000;320:527-8. (26 February.)

5 McWhinney IR. An introduction to family medicine. Oxford:

Oxford University Press, 1981:95-6.

\section{Voluntary organisations already help set policy in Scotland}

EDITOR-Crombie and Coid's thought provoking editorial on voluntary organisations asked whether such organisations should "be involved in planning and implementing policy."1 In Scotland they have been involved for at least the past four years in planning mental health services.

In 1996 the Scottish Office set up the Mental Health Reference Group to comment on early drafts of the Framework for Mental Health Services in Scotland, which was published in 1997. This external group comprises representatives from a number of agencies including the NHS, social workers, housing officers, people who use mental health services and the people who care for them, and representatives from the voluntary sector. Thus, voluntary sector organisations were able to shape policy.

The framework set out a coordinated planning process for the next two planning cycles (six years). Joint commissioning teams in each health board area in Scotland include representatives from the health board, the NHS, the local authority, service users, carers, and representatives from the voluntary sector. In fact, more than half of the membership of the Scottish Borders joint commissioning teams comprises users, carers, and representatives from the voluntary sector.

This is a time consuming exercise, but it is producing examples of real partnership and coordinated work in planning and delivering services. The reference group has continued to meet to take forward the framework's agenda.

Thus the voluntary sector is already fully engaged in planning and implementing policy in Scotland.

Ian Pullen consultant psychiatrist

Mental Health Reference Group, Borders Primary Care NHS Trust, Melrose TD6 9BD ipullen@hotmail.com

1 Crombie IK, Coid DR. Voluntary organisations: from Cinderella to white knight? BMJ 2000;320:392-3. (12 February.)

2 Scottish Office. Framework for mental health services in Scotland (1997). Edinburgh: Stationery Office, 1997.

\section{Managing patients with lung cancer}

\section{All evidence was considered when COIN guidelines were drawn up}

EDITOR-I chair the clinical oncology information network (COIN), the group that produced the COIN guidelines on the management of lung cancer on behalf of the Royal College of Radiologists. ${ }^{1}$ These guidelines were the subject of an editorial by Simmonds ${ }^{2}$ and later correspondence. ${ }^{3}$ I wish to add a few comments.

In their letter Ardizzoni et al take the guidelines to task on three specific issues. We carefully reviewed the evidence on the value of adding chemotherapy to radical radiotherapy for locally advanced non-small cell lung cancer. We thought that the evidence for a clinically important effect was not compelling, and we therefore recommended including patients in clinical trials but said, "If these are not available, induction chemotherapy is recommended."
The issue of chemotherapy for patients with stages IIIb and IV non-small cell lung cancer is more complex. At the time of writing we had strong (level Ia) evidence of only a modest effect on survival, with no clear evidence of benefit in terms of quality of life, as Constantini et al point out in their letter. This led us, after considerable discussion within the group and outside it, to recommend that patients should "normally be offered chemotherapy in the context of a clinical trial." Similarly, we thought that the evidence suggested that the benefit from thoracic radiotherapy for patients with small cell lung cancer with a good prognosis would most likely be in those who had achieved a complete response to chemotherapy.

Finally, I disagree with Ardizzoni et al's suggestion, endorsed by Simmonds in his reply to the letters, ${ }^{3}$ that there should be international guidelines. Whereas a systematic review should provide an objective summary of available research evidence, a guideline tries to synthesise this into recommendations for local clinical practice. In that respect, a guideline needs to be specific to the healthcare context for which it is intended. In the United Kingdom, for various reasons, few patients with non-small cell lung cancer currently get chemotherapy or radical radiotherapy. We thought that our responsibility was to make recommendations that would:

- Appreciably improve routine clinical practice and so benefit patients

- Be likely to be implemented

- Not be dismissed as the extreme views of superspecialists.

The contexts in the United Kingdom are different from those in mainland Europe and North America, and therefore the recommendations, based on the same research evidence, may well be different. No one is necessarily right or wrong. We are, as in so much else, just different.

Fergus Macbeth consultant oncologist Velindre Hospital, Whitchurch, Cardiff CF14 7XL fergus.macbeth@velindre-tr.wales.nhs.uk

Royal College of Radiologists' Clinical Oncology Information Network. Guidelines on the non-surgical management of lung cancer. Clin Oncol 1999;11:S1-53.

2 Simmonds P. Managing patients with lung cancer. BMJ 1999:319:527-8.

3 Managing patients with lung cancer [letters]. BMJ 2000;320:379-80. (5 February.)

\section{Guidelines must help bring us in line} with European standards

EDITOR-The COIN guidelines for lung cancer were published in 1998. An editorial and a letter ${ }^{2}$ in the $B M J$ have helped us focus on the implications of these guidelines for patients with lung cancer and oncologists in the United Kingdom. The guidelines, like other aspects of medicine, must be evidence based and present the data accurately, honestly, and impassionately; management decisions should be made with full knowledge of the data by appropriately trained oncologists.

The meta-analysis of chemotherapy for non-small cell lung cancer published in $1995^{3}$ represents level IA evidence (not IB 
as stated in the guidelines), and chemotherapy based on cisplatin should have a grade A recommendation for patients with both locally advanced and metastatic disease. The survival gain can only be interpreted, but not changed, in the light of quality of life data available now or in the future.

Unfortunately, the current guidelines do not reflect the evolution of practice over the past five years and therefore do not represent current management in certain areas. The main areas of concern are the use of chemotherapy for the palliative treatment of non-small cell lung cancer and the use of combined chemotherapy and radiotherapy for locally advanced non-small cell lung cancer and small cell lung cancer in suitable patients, as pointed out by European colleagues. ${ }^{2}$ We believe that the current guidelines confuse the issues and may well serve to maintain the nihilism surrounding lung cancer in the United Kingdom. This nihilism still means that:

- Many patients with lung cancer never see an oncologist

- Many patients' disease is not staged by computed tomography

- Oncologists with training in and enthusiasm for lung cancer are in short supply

- Combined modality treatments (radical radiotherapy and chemotherapy) are not routinely used where appropriate for both non-small cell lung cancer and small cell lung cancer

- Suitable patients are not offered chemotherapy for palliation

- Purchasers can now use these guidelines to deny funding for patients with lung cancer;

- Unlike those working elsewhere in Europe and North America, we in the United Kingdom cannot move the subject forward or contribute to the development of new drug regimens.

The five year survival figures for lung cancer in England and Scotland (6-7\%) are lower than those in our nearest European countries (France 14\%). The treatment of lung cancer in the United Kingdom is patchy, with chest physicians the gatekeepers. Guidelines must accurately represent the evidence and help bring us in line with European standards. The current COIN guidelines are inaccurate and do not reflect the views or practice of many lung cancer oncologists.

Mary E R O'Brien consultant medical oncologist Royal Marsden NHS Trust, Sutton, Surrey SM2 5PT

Maryo@icr.ac.uk

Michael Cullen consultant medical oncologis Queen Elizabeth Hospital, Birmingham BT12 2TH

1 Simmonds P. Managing patients with lung cancer. $B M$ J 1999;319:527-8.

2 Ardizzoni A, Grossi F, Salvati F, Silvano G, Santi L. Managing patients with lung cancer: Common international guidelines must be developed. BMJ 2000;320:379-80. (5 February.)

3 Non-small Cell Lung Cancer Collaborative Group Chemotherapy in non-small cell lung cancer: a metaanalysis using updated data on individual patients from 52 randomised clinical trials. BMJ 1995;311:899-909.

\section{Is norethisterone a lifestyle drug?}

\section{Health is not merely the absence of} disease

EDITOR-The summer peak in norethisterone prescribing shown so graphically by Shakespeare et al will not surprise most general practitioners. ${ }^{1}$ Although there is evidence that norethisterone is ineffective in reducing menstrual loss in menorrhagia, the drug is licensed and is effective at delaying the onset of menstruation and regulating chaotic or short menstrual cycles."

It is, in our opinion, insulting to women to imply that the use of norethisterone to postpone menstruation-which may account for a substantial proportion of current prescriptions of the drug-is inappropriate for the NHS.

Menstrual bleeding disorders are common and are often not associated with any recognised organic disease process: dysfunctional uterine bleeding is an acceptable diagnosis. Problem periods result in physical and psychological disease.

In Southern Derbyshire Health Authority, focus groups informed the development of our guidelines for menstrual bleeding problems. ${ }^{4}$ Women with problem periods perceived that their symptoms were often disregarded by health professionals. Positive outcomes desired from treatment were to have a regular cycle, without restrictions on their social functioning and sex lives.

In this era of patient centred care, once serious disease has been excluded many women choose to put up with their problem periods most of the time. However, for a few weeks of the year they may decide to take a holiday from periods.

Tranexamic acid used to treat menorrhagia for one year costs as much as $£ 100$ whereas norethisterone to delay a period may cost only $£ 5 .{ }^{3}$ It could be argued that women who tolerate their symptoms for most of the year but who take a period holiday make efficient use of NHS resources.

Health is not merely the absence of disease, but a positive concept of wellbeing. Norethisterone used to delay a period is no more a "lifestyle treatment" than other activities of the NHS aimed at promoting health.

Gerry Bryant specialist registrar in public health medicine

Leicestershire Health Authority, Leicester LE5 4OF gerry.bryant@mail.leicester-ha.trent.nhs.uk

Ian Scott consultant in obstetrics and gynaecology Derby City General Hospital, Derby DE22 2NE

Anne Worrall specialist registrar in public health medicine

Nottingham Health Authority, Nottingham NG1 6GN

1 Shakespeare J, Neve E, Hodder K. Is norethisterone a lifestyle drug? Results of database analysis. BMJ 2000;320:291. (29 January.)

2 NHS Centre for Reviews and Dissemination. The management of menorrhagia. Effective Health Care 1995; No 9. [August 1995]

3 British Medical Association, Royal Pharmaceutical Society of Great Britain British National Formulary. London: BMA, RPS, 1999:331-3. (No 38.)
4 Southern Derbyshire Health Authority. Clinical guidelines in Southern Derbyshire. The management of menstrual bleeding disorders. Derby: SDHA, 1997

5 World Health Organization. Constitution. Geneva: WHO, 1946

The term lifestyle is not as clear as it may seem

EDITOR-Shakespeare et al showed a summer peak in norethisterone prescribing in their study. ${ }^{1}$ Their study did not seek to determine the indication for these prescriptions so they had to surmise that the summer peak was a result of prescriptions for delaying menstruation over the main holiday period.

Data from our practice suggest that their interpretation is correct. From a list of 6450 patients this practice issued 58 prescriptions for norethisterone $5 \mathrm{mg}$ to 43 women between January 1998 and December 1999. Our practice policy is to include an indication for all prescriptions; 27 of the 58 $(47 \%)$ were for postponement of menstruation. The 20 women whose indication was postponement of menstruation had a mean age of 35 (95\% confidence interval 29 to 41 years). This seems surprisingly old, until you consider that users of the combined oral contraceptive can avoid untimely menstruation by omitting the gap between packets of their pill-so called bicycling.

This adds another dimension to the debate over "lifestyle" drugs. If postponing menstruation is a lifestyle issue (and, by inference, something that the NHS should hesitate to offer) we must acknowledge that some women, predominantly younger women, can achieve the desired effect through a non-lifestyle drug.

William Hamilton general practitioner Barnfield Hill Surgery, Exeter EX1 1SR barnfield.hill.research@which.net

1 Shakespeare J, Neve E, Hodder K. Is norethisterone a lifestyle drug? Results of database analysis. BMJ 2000:320:291. (29 January.)

It's not a lifestyle drug in North Harrow

EDITOR-In response to Shakespeare et al's study on norethisterone prescribing, ${ }^{1}$ I may be a bloke but many of my patients are keen not to have a period during their holidays - a well known time of stress. Records on our surgery computer show that we have prescribed norethisterone to postpone menstruation 194 times since 1988 to 140 different women. And I shall continue to do so.

David Lloyd general practitioner

Ridgeway Surgery, North Harrow HA2 7DU

david@ridgeway-surgery.demon.co.uk

1 Shakespeare J, Neve E, Hodder K. Is norethisterone a lifestyle drug? Results of database analysis. BMJ 2000;320:291. (29 january.)

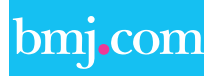

\section{Rapid responses}

Correspondence submitted electronically

is available on our website 